Research article

Open Access

\title{
Genomic profiling of breast tumours in relation to BRCA abnormalities and phenotypes
}

\author{
Olafur Andri Stefansson ${ }^{1}$, Jon Gunnlaugur Jonasson², Oskar Thor Johannsson ${ }^{3}$, \\ Kristrun Olafsdottir ${ }^{2}$, Margret Steinarsdottir ${ }^{4}$, Sigridur Valgeirsdottir ${ }^{5}$ and Jorunn Erla Eyfjord ${ }^{1}$
}

${ }^{1}$ Faculty of Medicine, University of Iceland, Vatnsmyrarvegur 16, Reykjavik, Iceland

2Department of Pathology, Landspitali University Hospital, Hringbraut, Reykjavik, 101, Iceland

${ }^{3}$ Department of Oncology, Landspitali University Hospital, Hringbraut, Reykjavik, 101, Iceland

${ }^{4}$ Department of Genetics and Molecular Medicine, Landspitali University Hospital, Hringbraut, Reykjavik, 101, Iceland

${ }^{5}$ Roche NimbleGen, Inc., Vínlandsleið 2-4, Reykjavik, 113, Iceland

Corresponding author: Jorunn Erla Eyfjord, jorunne@hi.is

Received: 19 Nov 2008 Revisions requested: 7 Jan 2009 Revisions received: 27 Apr 2009 Accepted: 9 Jul 2009 Published: 9 Jul 2009

Breast Cancer Research 2009, 11:R47 (doi:10.1186/bcr2334)

This article is online at: http://breast-cancer-research.com/content/11/4/R47

(c) 2009 Stefansson et al.; licensee BioMed Central Ltd.

This is an open access article distributed under the terms of the Creative Commons Attribution License (http://creativecommons.org/licenses/by/2.0), which permits unrestricted use, distribution, and reproduction in any medium, provided the original work is properly cited.

\begin{abstract}
Introduction Germline mutations in the BRCA1 and BRCA2 genes account for a considerable fraction of familial predisposition to breast cancer. Somatic mutations in BRCA1 and BRCA2 have not been found and the involvement of these genes in sporadic tumour development therefore remains unclear.

Methods The study group consisted of 67 primary breast tumours with and without BRCA1 or BRCA2 abnormalities. Genomic alterations were profiled by high-resolution ( $7 \mathrm{kbp})$ comparative genome hybridisation $(\mathrm{CGH})$ microarrays. Tumour phenotypes were analysed by immunohistochemistry on tissue microarrays using selected biomarkers (ER, PR, HER-2, EGFR, CK5/6, CK8, CK18).

Results Classification of genomic profiles through cluster analysis revealed four subgroups, three of which displayed high genomic instability indices (GII). Two of these Gll-high subgroups were enriched with either BRCA1- or BRCA2related tumours whereas the third was not $B R C A$-related. The $B R C A 1$-related subgroup mostly displayed non-luminal phenotypes, of which basal-like were most prominent, whereas the other two genomic instability subgroups BRCA2- and Gllhigh-III (non-BRCA), were almost entirely of luminal phenotype. Analysis of genome architecture patterns revealed similarities between the BRCA1- and BRCA2 subgroups, with long

deletions being prominent. This contrasts with the third instability subgroup, not $B R C A$-related, where small gains were more prominent.

Conclusions The results suggest that BRCA1- and BRCA2related tumours develop largely through distinct genetic pathways in terms of the regions altered while also displaying distinct phenotypes. Importantly, we show that the development of a subset of sporadic tumours is similar to that of either familial $B R C A 1$ - or BRCA2 tumours. Despite their differences, we observed clear similarities between the BRCA1- and BRCA2related subgroups reflected in the type of genomic alterations acquired with deletions of long DNA segments being prominent. This suggests similarities in the mechanisms promoting genomic instability for BRCA1- and BRCA2-associated tumours, possibly relating to deficiency in DNA repair through homologous recombination. Indeed, this feature characterized both familial and sporadic tumours displaying BRCA1- or $B R C A 2-l i k e$ spectrums of genomic alterations. The importance of these findings lies in the potential benefit from targeted therapy, through the use of agents leading to DNA doublestrand breaks such as PARP inhibitors (olaparib) and cisplatin, for a much larger group of patients than the few BRCA1 and BRCA2 germline mutation carriers.
\end{abstract}

CBS: circular binary segmentation; CGH: comparative genomic hybridisation; CK: cytokeratin; EGFR: epidermal growth factor receptor; ER: oestrogen receptor; FISH: fluorescence in situ hybridiaation; Gll: genomic instability index; HER: human epidermal growth factor receptor; IHC: immunohistochemisty; MSP: methylation-specific PCR; PCA: principal component analysis; PR: progesterone receptor; TMA: tissue microarrays. 


\section{Introduction}

Germline mutations in the BRCA1 or BRCA2 genes significantly increase the risk of developing early-onset breast cancer [1]. Tumours derived from BRCA1 or BRCA2 germline mutation carriers have generally lost the wild-type $B R C A 1$ or $B R C A 2$ alleles, respectively $[2,3]$. These observations suggest important roles for the BRCA1 and BRCA2 genes as tumour suppressors. The $B R C A 1$ and $B R C A 2$ gene products are both phosphorylated by ATR (ataxia telangiectasia and Rad3 related) which, in turn, is activated by DNA damage and stalled replication forks $[4,5]$. BRCA1 is important in recruitment of various DNA repair proteins, including BRCA2, to sites of DNA damage, whereas BRCA2 is crucial for catalysing the formation of RAD51 filaments on single-stranded DNA at the damaged sites $[6,7]$. The BRCA1 and BRCA2 proteins are linked within a network of protein interactions having a common objective of responding to DNA damage and stalled replication forks [8]. Disruption of key elements within this network might explain why cells defective in either BRCA1 or BRCA2 display genomic instability and are sensitive to DNA damage that involves double-strand breaks [4]. This has suggested potential therapeutic applications through the use of agents that lead to double-stranded DNA breaks such as PARP inhibitors, mitomycin $\mathrm{C}$ and platinum salts [9].

The involvement of the BRCA1 and BRCA2 genes in sporadic breast tumour development has been questioned because somatic mutations in BRCA1 or BRCA2 have not been found $[10,11]$. However, methylation of the BRCA1 gene promoter and loss of BRCA1 gene expression are significantly associated and occur frequently in sporadic breast tumours [12]. We have previously reported on epigenetic silencing of the BRCA1 gene through promoter methylation in about $10 \%$ of an unselected set of sporadic breast cancers [13]. These observations suggest that epigenetic silencing of the BRCA1 gene might be an alternative to somatic mutations as a mechanism of $B R C A 1$ inactivation in sporadic cases of breast cancer. In addition, it has been demonstrated that the BRCA2 gene is negatively regulated by protein interactions with gene products of the EMSY gene which, in turn, is frequently amplified in sporadic breast tumours [14]. This suggests an important link between the BRCA2 gene and sporadic tumour development.

Analyses of genomic and gene expression profiles in unselected sets of breast tumours have revealed subgroups of biological and clinical relevance $[15,16]$. These studies have shown that the expression profiles of tumours derived from $B R C A 1$ germline mutation carriers strongly resemble those of sporadic basal-like tumours [17]. This has suggested that underlying BRCA1 abnormalities could promote sporadic basal-like tumour development. Supporting this notion is the finding that sporadic basal-like tumours frequently display a significantly reduced expression of the BRCA1 gene and genomic instability $[18,19]$. However, a subset of sporadic basal-like tumours do not display large-scale genomic instability which have been proposed to represent a novel subtype of breast cancers [20]. Here, we have profiled and examined the patterns of genomic alterations in familial BRCA1 and BRCA2 tumours in the context of sporadic tumours with and without epigenetic silencing of the BRCA1 gene. The results were coupled with analysis of tumour phenotypes using a selected set of biomarkers on tissue microarrays. We then specifically addressed the question of whether the BRCA1 and BRCA2 genes are involved in sporadic breast tumour development.

\section{Materials and methods Study group}

The study group was derived from a well-defined population with respect to the local BRCA1 5193G->A and BRCA2 999de/5 germline mutations [21,22]. All patients within the study group had previously been screened for these BRCA1 and BRCA2 germline mutations. Sporadic tumours were defined as those derived from patients that were negative for the local BRCA germline mutations with no known family history of the disease.

The study group consisted of a selected set of primary infiltrating female breast tumour samples $(n=67)$. The samples were selected from tumours derived from BRCA1 and BRCA2 germline mutation carriers along with sporadic tumours with and without epigenetic silencing of the BRCA1 gene. At least one sporadic tumour $(\mathrm{n}=38)$ without $B R C A$ abnormalities was selected for each of the $B R C A$ abnormal tumours ( $\mathrm{n}=$ $29)$, that is, familial BRCA1 $(\mathrm{n}=3)$ and $\operatorname{BRCA2}(\mathrm{n}=18)$ tumours along with sporadic tumours displaying epigenetic silencing of the BRCA1 gene $(n=8)$. All tumours, sporadic and familial BRCA1 and BRCA2, were selected by their patient age at diagnosis of 61 years or younger. The DNA samples had previously been isolated from freshly frozen tumour tissue and these samples were obtained from the Biological Specimen Bank of the Icelandic Cancer Society. The tumour samples were macroscopically examined prior to DNA isolation and portions showing viable tumour tissue were identified. These portions were then selected for DNA isolation, which was performed using a standard phenol-chloroform plus proteinase $\mathrm{K}$ protocol. Data on clinical parameters were obtained from the Department of Pathology and Department of Oncology, Landspitali Hospital, Reykjavik, Iceland. Time to relapse refers to the time from surgical removal of the primary tumour to diagnosis of recurrence or metastasis. This work was carried out according to permits from the Icelandic Data Protection Commission (2006050307) and Bioethics Committee (VSNb2006050001/03-16). Informed consent was obtained from all patients. 


\section{Array comparative genomic hybridisation}

Comparative genomic hybridisation $(\mathrm{CGH})$ was performed using high-resolution oligonuclueotide microarrays (Roche NimbleGen, Inc., Reykjavik, Iceland) [23]. The arrays used, "2006_11_01 HG17_WG_CGH" (n = 46) and "080101 HG18_WG_CGH_v2_X1" $(n=21)$, were of a standard design developed by Roche NimbleGen, Inc. (Reykjavik, Iceland) covering the human genome in about $7 \mathrm{kbp}$ median resolution. Sample preparations and hybridisations were carried out according to manufacturer's protocols (NimbleGen Arrays User's Guide-CGH Analysis, Roche NimbleGen, Inc., Reykjavik, Iceland). Сy3 and Cy5 signal intensity distributions were then normalized using the qspline method (affy package in Bioconductor for R) [24]. The array CGH data are available in the ArrayExpress repository (E-TABM-712).

\section{Methylation specific PCR and allelic imbalance}

Methylation at the BRCA1 promoter region was assessed in all tumours within the study group by methylation-specific PCR (MSP) as previously described [13]. Allelic imbalance by microsatellite analysis at the BRCA1 and BRCA2 loci had previously been performed [13].

\section{Tissue microarrays and expression analysis}

Core samples were removed $(1.0 \mathrm{~mm}$ diameter) from each tumour and rearranged on empty paraffin-blocks using a manual tissue microarray device (BEECHER MTA II; Beecher Instruments, Inc., Sun Prairie, Wisconsin, USA).

Immunohistochemistry (IHC) was applied to $4 \mu \mathrm{m}$ thick tissue microarray (TMA) sections mounted on superfrosted slides (Menzel, Germany). The slides were dewaxed and immerged in Tris-EDTA, pH 9, (HIER) in microwave oven at $99^{\circ} \mathrm{C}$. Endogenous peroxidase activity was inactivated by incubation in blocking solution and the slides then incubated with primary antibody (30 minutes). Polymer conjugate was used as Visualization System (K4061, EnVision+ Dual Link, DAKO, DK2600, Glostrup, Denmark) (30 minutes) and DAB (K-3468, DAKO, DK-2600, Glostrup, Denmark) used as chromogen (10 minutes).

Expression analysis by IHC on TMA sections was performed for oestrogen receptor (ER), progesterone receptor (PR), human epidermal growth factor receptor (HER)-2, epidermal growth factor receptor (EGFR), cytokeratin (CK) 5/6, CK8, CK18 and BRCA1 [see Additional data file 1]. Expression levels were estimated blindfolded to previously established tumour characteristics and BRCA abnormalities. Expression of $E R$ and $P R$ were scored on a discontinuous scale of $0+, 1+$, $2+$ and $3+$ with the addition of hyper-intense staining $(>3+)$ being remarked for those tumours displaying extremely intense and concentrated nuclear staining. Positive nuclear ER and $\mathrm{PR}$ immunostaining was defined as any visible staining in more than $1 \%$ of tumour cell nuclei. Information obtained from Landspitali Hospital, Department of Pathology (ligand binding assay) was used to complement missing data on ER and PR expression thereby allowing ER and PR positivity/negativity to be established for all tumours within the study group. HER-2 positivity was defined as staining of tumour cellular membranes displaying a score of $3+$ according to criteria provided by the manufacturer (DAKO, DK-2600, Glostrup, Denmark). EGFR was scored on a discontinuous scale of $0+, 1+, 2+$ and $3+$ which was estimated by the staining intensity of tumour cellular membranes following descriptions provided by the manufacturer (DAKO, Glostrup, Denmark). EGFR positivity was defined as tumours displaying any, weak or strong, staining of the cellular membrane whereas a score of $2+$ or higher was defined as high EGFR expression. Expression of BRCA1 was estimated by nuclear staining where loss of BRCA1 expression was defined as no visible nuclear staining whereas positive expression was defined as any visible, weak or strong, nuclear staining. The CK5/6 marker was scored as positive when weak or strong cytoplasmic and/or membranous staining was visible and otherwise scored as negative. CK8 and CK18 were scored on a scale of $0+, 1+, 2+$ and $3+$ according to descriptions provided by the manufacturer (DAKO, Glostrup, Denmark).

\section{Definition of tumour phenotypes and BRCA abnormalities}

Luminal phenotype was defined as positivity for either ER or PR whereas non-luminal phenotype was defined as negativity for both ER and PR. The five biomarker classification scheme given in Cheang and colleagues was used to further subdivide these two phenotypic categories into luminal, luminal-HER2, 5NP (five-marker negative phenotype), non-luminal HER2 and basal-like phenotypes [25].

Tumours derived from $B R C A 1$ and $B R C A 2$ germline mutation carriers were defined as BRCA1 and BRCA2 abnormal, respectively. Additionally, tumours displaying epigenetic silencing of the BRCA1 gene were defined as BRCA1 abnormal in those cases where BRCA1 promoter methylation was coupled with complete absence of nuclear BRCA1 protein expression.

\section{Fluorescence in situ hybridisation}

Fluorescence in situ hybridisation (FISH) was performed on paraffin-embedded and formalin-fixed tumour tissue sections $(4 \mu \mathrm{m})$. DNA probe specific for the EMSY gene (BAC human CTD 2501F13, Invitrogen, Carlsbad, CA, USA) was labelled with SpectrumOrange-dUTP (Vysis, Des Plaines, IL, USA) by nick translation, and pRB11 clone for the centromere of chromosome 11 labelled with fluorescein-12-dUTP (Enzo Life Sciences, Farmingdale, NY, USA). Slides were deparaffinised and pretreated, probes and cotl DNA denatured in t-DenHyb2 hybridisation buffer (Insitus Biotechnologies, Albuquerque, NM, USA) and hybridised to the tumour sections overnight. Stringency wash was performed at $72^{\circ} \mathrm{C}$ in solution containing $2 \times \mathrm{SSC} / 0.3 \% \mathrm{NP}-40$. Analysis was performed in a Leica 
DMRXA2 fluorescence microscope with at least 100 cell nuclei counted in each experiment. Thresholds for copy gains were set at gene/centromere ratio of more than 1.5 and highlevel amplification at a ratio of more than 2.5.

\section{Statistical analysis and data mining of array-CGH data}

The Cy3/Cy5 ratio signal intensities were log2 transformed following normalisation of each array $\mathrm{CGH}$ experiment. The data were then represented by the median of $\log 2$ ratios within a window of five probes resulting in a median resolution of about $37.5 \mathrm{~kb}$. Copy number alterations were identified by the Circular Binary Segmentation (CBS) algorithm implemented in DNAcopy (Bioconductor for R) with an alpha of 0.01 to identify change points while cancelling splits having less than 1.0 standard deviation units in difference through the sd.undo procedure $[24,26]$. The threshold for determining copy number alterations was fixed at \pm 0.08 , which was selected to capture the level of plateaus above and below the baseline as observed within the examined tumour genomes [26]. To further refine these thresholds we obtained estimates of probe noise levels for each of the arrays as described in Fridlyand and colleagues [27] to subsequently categorise the arrays by their noise levels with the discriminators being the lower and upper quartiles of the distribution. The thresholds for arrays displaying high and low noise levels were then modified to \pm 0.10 and \pm 0.06 , respectively. The assigned thresholds were then validated by examining the association between immunostaining scores of the HER-2 gene (HercepTest, DAKO, DK-2600, Glostrup, Denmark) and copy number states, that is, gains, no change and deletions, which was found to be highly significant (Pearson's correlation, $r=0.53, P=3.2 \times$ $\left.10^{-5}\right)$. Additionally, we found the frequency of copy number gains at the HER-2 gene locus to be $27 \%$ (18 of 67), which is in line with previous reports [20]. High-level amplifications were defined as segment means that exceed 2SD units above the mean of $\log _{2}$ ratios derived from segments gained in copy number. These thresholds were validated by examining the association between HER-2 overexpression (HercepTest, Score $3+$ ) and high-level amplification of the HER-2 gene (Pearson's correlation, $r=0.64, P=1.3 \times 10^{-7}$ ).

The CBS output was then used to represent each of the tumour genomes as segmented profiles in terms of copy number states, that is, +1 for copy gains, 0 for no change and -1 for deletions. Copy number alterations often cover large genomic regions within which a subset of one or more genes may be targeted [28]. Thus, classification of genomic profiles is subject to a large degree of inherent biological noise. This was addressed by projecting the data to lower dimensions through principal component analysis (PCA) prior to cluster analysis making use of only the first few components. This was performed in R 2.7.2 where the prcomp function was used to obtain the components. The first three principal components explained about $40 \%$ of the variability in the genomic data [see Additional data file 2]. Each of the other components explained less than $5 \%$ of the variability and were ignored in the subsequent steps. Cluster analysis was performed on the lower-dimensional data using the $k$-means cluster algorithm in $R$ 2.7.2. This was carried out in an iterative procedure where the silhouette information was estimated using the silhouette function in R 2.7.2 (cluster package) to establish strong and reproducible results. Average silhouette information was used to identify the number of clusters in the data with 1000 iterations for each $k=\{2,3, \ldots, 10\}$. Tumours with a low silhouette information (silhouette $<0.20$ ) were considered borderline instances and were classified by first filtering the data in a Kruskal-Wallis hypothesis test $(P<0.01)$ while leaving out all such borderline tumours and then determining their membership position by re-applying the cluster procedure. A final model was then derived through the same procedure resulting in all tumours being assigned a cluster membership indicator.

To compensate for the few samples derived from BRCA1 germline mutation carriers in our study we obtained previously published array $\mathrm{CGH}$ data available online through ArrayExpress (E-TABM-170). This dataset included genomic profiles derived from five familial BRCA1 tumours, which were combined with our dataset. These five familial BRCA1 tumours were analysed by first identifying copy number alterations as described in Fridlyand and colleagues [27]. The output was then used to represent each of the tumour genomes as segmented profiles in terms of copy number states as described above. These segmentation profiles were then combined with our dataset by obtaining copy number states from each of the tumour genomes analysed in this study representing the nearest genomic region to those represented on the $\mathrm{CGH}$ arrays used in the Fridlyand and colleagues study [27]. This was performed by determining the difference in genomic length for each location between the two array platforms and then selecting the minimal distance. This procedure reduces the median array resolution from about $7 \mathrm{~kb}$ to about $765 \mathrm{~kb}$, that is, from the NimbleGen high-resolution design to that used in Fridlyand and colleagues [27].

The degree of genomic instability for each tumour was estimated by determining the fraction of the genome altered. This was computed by obtaining copy number states for each of the windowed probes and determining the number of those assigned as altered in copy number against the total number of windowed probes. This measure, referred to as the genomic instability index (GII), has been described previously [20].

Genomic alterations characterising each of the subgroups were identified by using a conservative modification of the Fisher's exact test with $P \leq 0.001$, which was applied on the filtered dataset. This conservative modification of the Fisher's exact test has the advantage of penalising low $P$-values based on few counts [29]. 
Figure 1
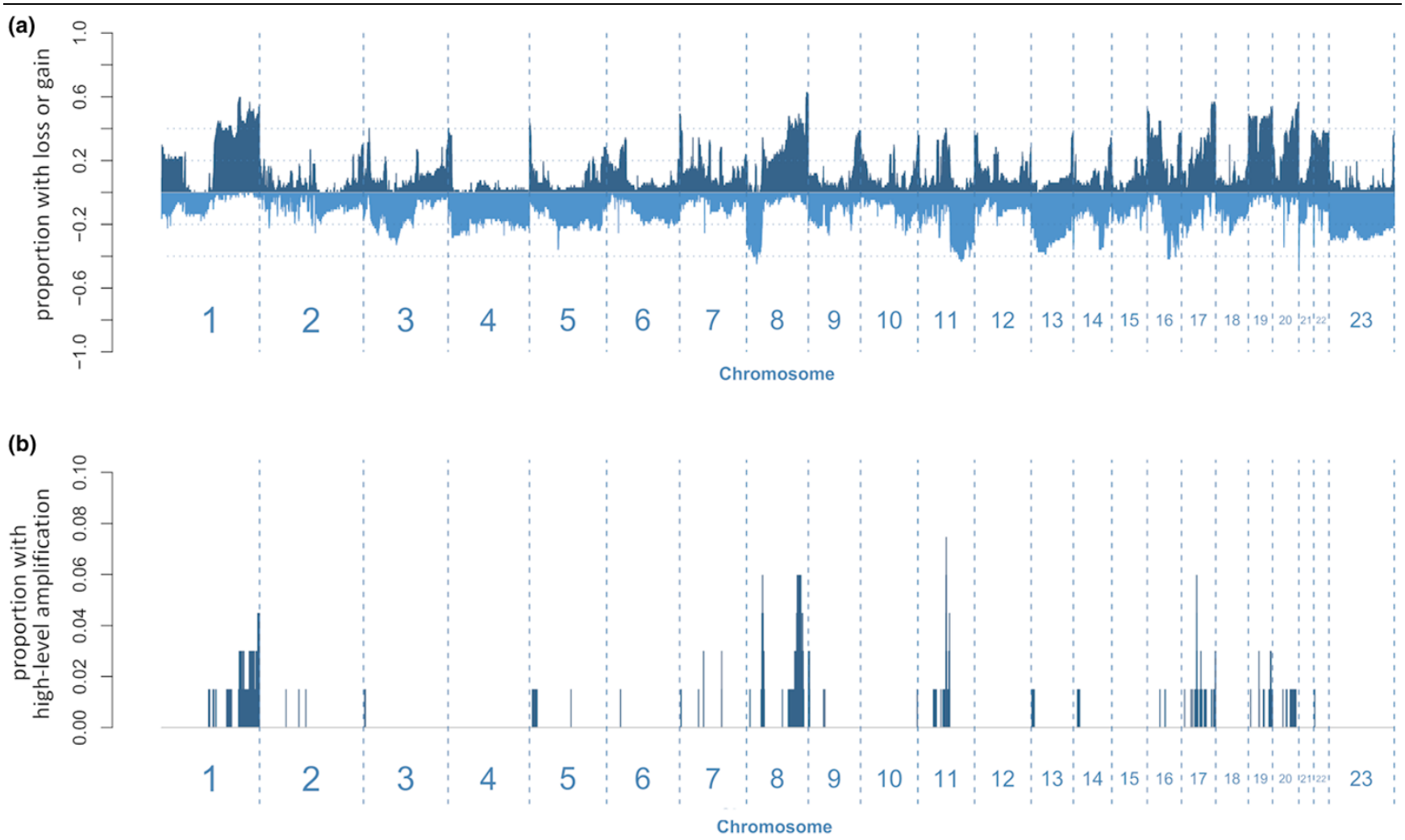

Genomic alterations within the study group. (a) The proportion of tumours with copy gains (positive) or deletions (negative) plotted along each chromosome. (b) The proportion of tumours with high-level amplifications plotted along each chromosome.

\section{Results \\ Copy number alterations in breast tumour genomes}

Genomic alterations present within the study group were visualised by generating a frequency plot displaying the proportion of tumours with copy number gains and deletions at each genomic location analysed (Figure 1a). Examination of the frequency plot reveals that regions frequently gained are infrequently deleted and vice versa. It can also be seen that sites of recurrent high-level amplification events occur within genomic regions that are frequently gained in copy numbers (Figure 1b). These observations show that copy number alterations are not randomly distributed throughout the tumour genomes.

\section{Classification of genomic profiles}

Variability present in the spectrum of genomic alterations within the study group was examined by unsupervised classification of the genomic profiles through cluster analysis. The purpose was to examine the resulting tumour subgroups in terms of their prevalence for BRCA1 and BRCA2 abnormalities.

Cluster analysis revealed four distinct subgroups within the set of tumours constituting the whole study group (Figure 2a; see Additional data files 3 and 4 ). Three of the identified sub- groups displayed high levels of genomic instability as measured by the Gll, whereas one subgroup was characterised by low instability levels clearly seen in the distribution of Gll within this subgroup in comparison with that of the others combined (Wilcoxon rank sum test, $P<10^{-11}$; Figure $2 \mathrm{~b}$ ). One of the Gllhigh subgroups $(n=11)$ was enriched with tumours displaying $B R C A 1$ abnormalities (6 of 11) defined as an instance of a $B R C A 1$ germline mutation or epigenetic silencing of the $B R C A 1$ gene (Fisher's exact test, $P=0.006$ ). This subgroup will hereafter be referred to as the BRCA1-related subgroup. Tumours displaying epigenetic silencing of the BRCA1 gene were also highly enriched within this subgroup when sporadic cases were considered exclusively (Fisher's exact test $P=$ 0.007). Additionally, two other sporadic tumours within this subgroup displayed loss of BRCA1 protein expression without detectable hypermethylation of the BRCA1 gene promoter and both of these tumours were CK5/6 positive. All tumours within this subgroup analysed for loss of heterozygosity at the $B R C A 1$ locus displayed allelic imbalance (Fisher's exact test, $P=0.003$ ). To validate the relationship with $B R C A 1$ abnormalities we obtained previously published $\mathrm{CGH}$ array data in which five familial BRCA1 breast tumour samples were analysed [27]. The five familial BRCA1 tumours were combined with all the samples in our study group to subsequently reapply the clustering procedure [see additional data file 5]. All 

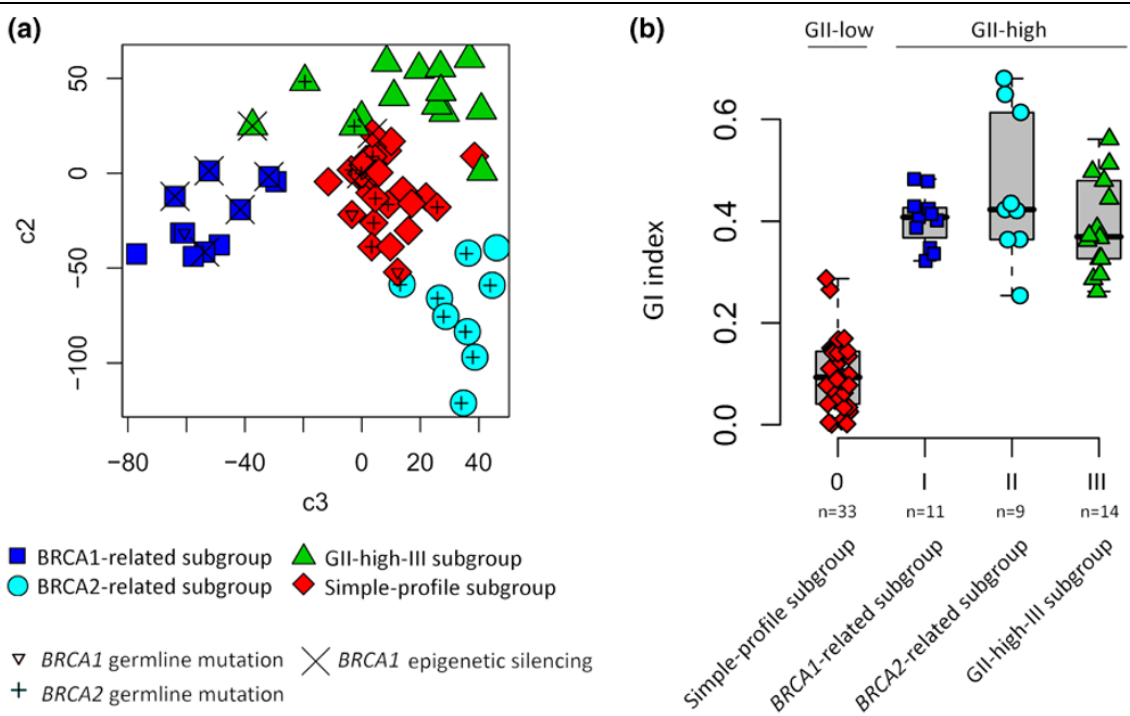

Classification of breast tumours by their genomic profiles through cluster analysis identified four distinct subgroups. (a) Cluster membership outcomes are visualised in terms of $B R C A$ abnormalities through principal component analysis (PCA). Two of the four identified subgroups were enriched for either $B R C A 1$ or $B R C A 2$ abnormalities referred to as the $B R C A 1$-related $(n=11)$ and $B R C A 2$-related subgroups ( $n=9)$, respectively. The characters represent cluster memberships of each tumour with BRCA1 and BRCA2 abnormaliti nt two reflects their similarities, see further in Additional data file 3. (b) The distribution of genomic instability indices (GII) differed considerably between the identified subgroups in that one of the subgroups displayed low genomic instability whereas the other three displayed high instability levels.

of the five familial BRCA1 tumours clustered among the tumours that constituted the previously defined subgroup of tumours enriched with BRCA1 abnormalities. Combining the two different platforms involves reduction in array resolution for which reasons the five familial $B R C A 1$ tumours were not included in subsequent analysis. A total of five blood-derived DNA samples from individuals with sporadic tumours displaying BRCA1-like genomic patterns were fully screened for germline mutations in the BRCA1 gene and none were found. Another Gll-high subgroup ( $\mathrm{n}=9$ ) was highly enriched of tumours derived from $B R C A 2$ germline mutation carriers ( 8 of 9; Fisher's exact test $P<10^{-4}$; Figures $2 \mathrm{a}$ and $2 \mathrm{~b}$ ). We will hereafter refer to this subgroup as the BRCA2-related subgroup. The third Gll-high subgroup $(n=14)$ was not related to abnormalities in the BRCA genes and will hereafter be referred to as the Gll-high-III subgroup (Figures 2a and 2b).

\section{Genomic alterations characterising the distinct genomic subgroups}

The genomic alterations that characterised the BRCA1related subgroup, when compared with the rest of the cohort, were deletions at chromosomes $4 p, 4 q, 5 p / q, X p, X q$ along with copy number gains at $10 p$ and $16 q$ (Fisher's exact test modified, $P<0.001$ ) [See Additional data files 6 and 7]. Genomic regions characterising the BRCA2-related subgroup were deletions at chromosomes 1p, 3p, 6q, 8p, 11q, $13 q, 14 q, 16 q, 17 p$ and $X p$ along with copy number gains at $3 p, 8 q$ and $17 q$ as compared with the rest of the cohort (Fisher's exact test modified, $P<0.001$ ) [see Additional data files 6 and 7]. High-level amplifications at 1q43-q44 and $8 q 24$ were prominent ( $>20 \%$ of samples) within the BRCA2related subgroup (Fisher's exact test, $P<0.05$ ). The one sporadic tumour that clustered among the $B R C A 2$-related subgroup displayed gains in copy numbers of the EMSY gene located at 11q13.5, which was confirmed by FISH analysis for two different regions of the tumour showing gene/centromere ratios of 1.9 and 3.0, respectively [see Additional data file 8]. Full sequencing of the BRCA2 gene was carried out on bloodderived DNA from this individual and no germline mutations were found.

The genomic alterations that characterised the GII-high-III subgroup were mostly small regions of copy number gains [see Additional data files 6 and 7]. High-level amplifications at 11q13.2-q13.3 were prominent ( $>20 \%$ of samples) within this subgroup (Fisher's exact test, $P<0.05$ ). All but two samples $(12$ of $14 ; 86 \%)$ within this subgroup displayed high- or low-level copy number gains at the 11q13.2-q13.3 genomic region (Fisher's exact test modified, $P=0.0003$ ). The highlevel amplifications at 11q13.2-q13.3 included two regions at which the level of significance peaks. One of these two regions covered a very small region, about $92 \mathrm{~kb}$, and included a single gene, the $F A D D$ gene whereas the second region covered about $556 \mathrm{~kb}$ and included four genes, that is, MYEOV, CCND1, ORAOV1 and FGF19.

The subgroup characterised by tumours with low Glls was not associated with any specific genomic alterations. Some of 
Figure 3

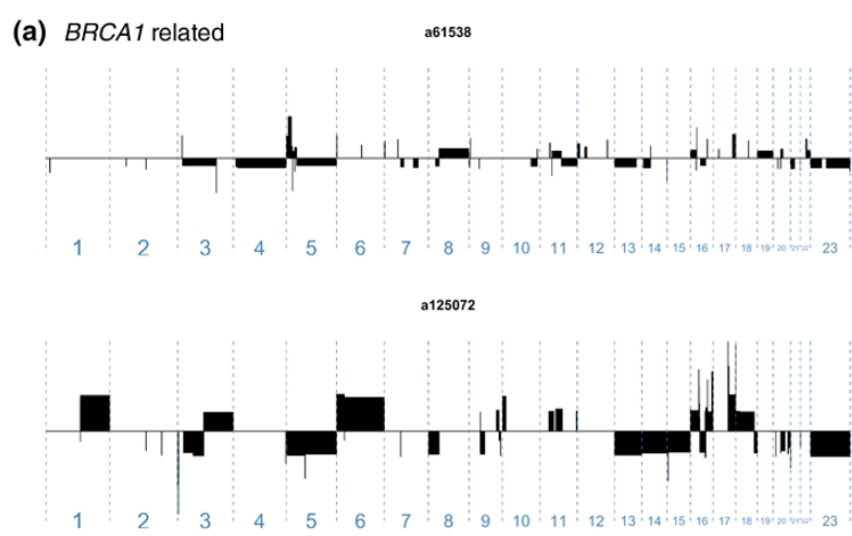

(c)

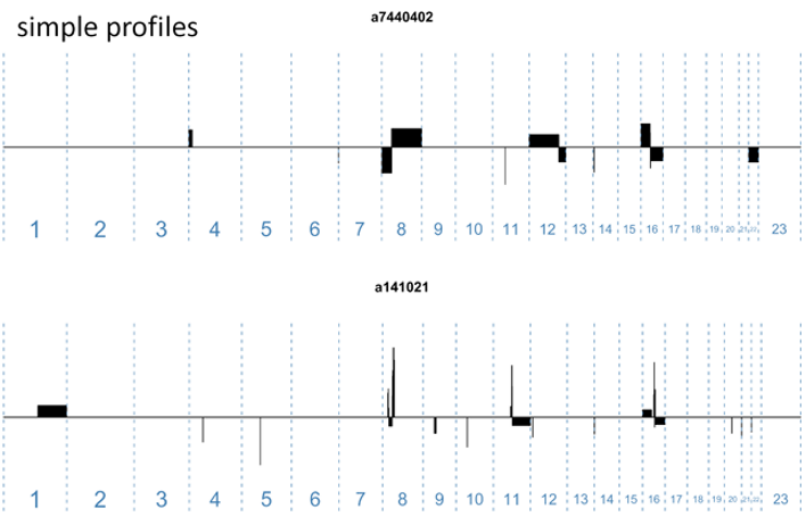

(b) BRCA2 related a7430002
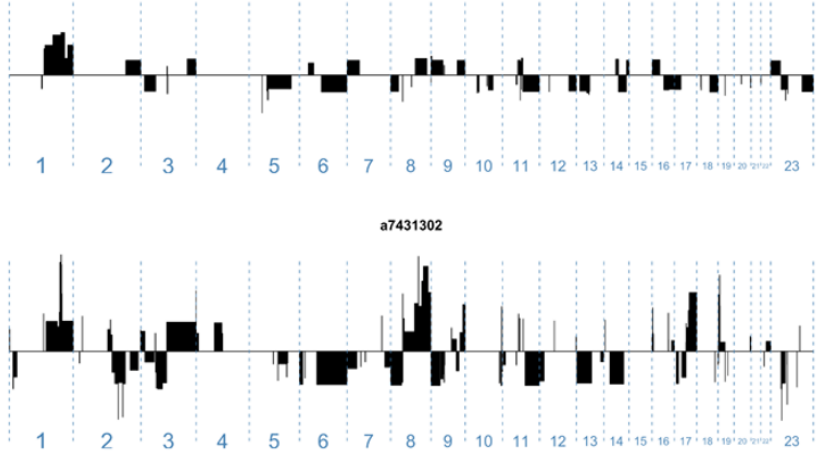

(d) GII-high-III

a123873
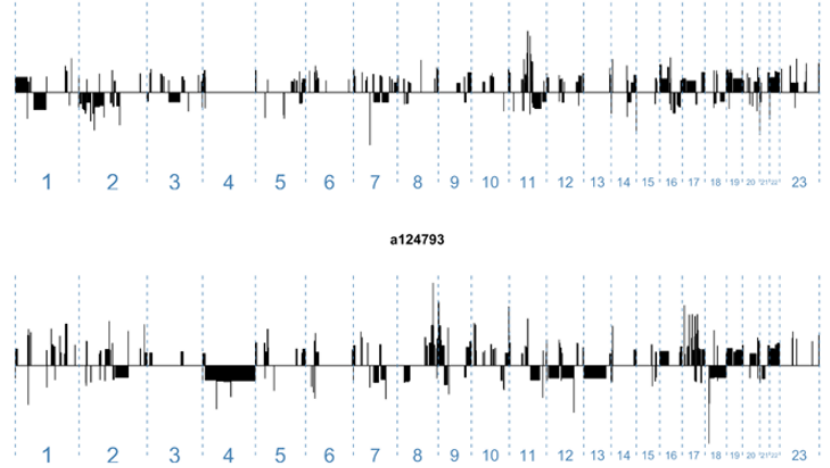

Differences in genome architecture patterns were observed between the identified subgroups. Two tumour genomes are shown for each of the four subgroups. (a) The BRCA1-and (b) BRCA2-related subgroups are characterised by relatively long segments of deletions with occasional high-level amplifications. (c) The simple-profile subgroup resembled the BRCA1-and BRCA2-related subgroups but displayed considerably less complex genomes. (d) The Gll-high-III subgroup was characterised by small and closely spaced segments of genomic alterations throughout their tumour genomes along with occasional high-level amplifications. Gll = genomic instability index.

these tumours displayed copy number gains at $1 \mathrm{q}, 8 \mathrm{q}$ and $16 p$ and deletions at $8 p$ and $16 q$. These genomic alterations do not all occur within the same tumour but different combinations of them describe the observed variation in genomic profiles found within this subgroup. It is important to note that we did observe tumours that did not display any of these commonly observed alterations with some having very few copy number alterations. We propose here that these tumours may represent biologically important disease entities of breast cancers.

\section{Genome architecture patterns}

Visual examination of the segmentation profiles revealed clear differences in alteration patterns between each of the identified subgroups, that is, their genome architecture patterns (Figure 3). Tumour genomes within the BRCA1- and BRCA2related subgroups were characterised by relatively long stretches of genomic alterations, deletions and copy gains along with occasional high-level amplifications (Figures $3 a$ and $3 b)$. Tumours within the simple-profile subgroup appear similar to the BRCA1 and BRCA2 subgroups in terms of altered seg- ment lengths but differ in that they display considerably less complex genomes (Figure 3c). The tumours within the Gllhigh-III subgroup were characterised by numerous closely packed and small copy number alterations throughout their genomes with occasional high-level amplification events (Figure $3 \mathrm{~d}$ ). This is similar to the complex-firestorm patterns described by Hicks and colleagues or the amplification phenotype described by Fridlyand and colleagues whereas the $B R C A 1$ and BRCA2-related subgroups are more similar to the complex-sawtooth patterns [30,31].

The observed phenotypic features of the tumour genomes were quantitatively analysed by examining the segment lengths within each subgroup. This analysis demonstrates that the distribution of segment lengths within the Gll-high-III subgroup is shifted towards smaller segments, whereas the tumours within the BRCA1-related subgroup display a shift towards longer segments (Figure 4a). Examining the segment lengths of deletions and gains separately shows that the $B R C A 1$ - and BRCA2-related subgroups are characterised by large deletions whereas the Gll-high-III subgroup is character- 

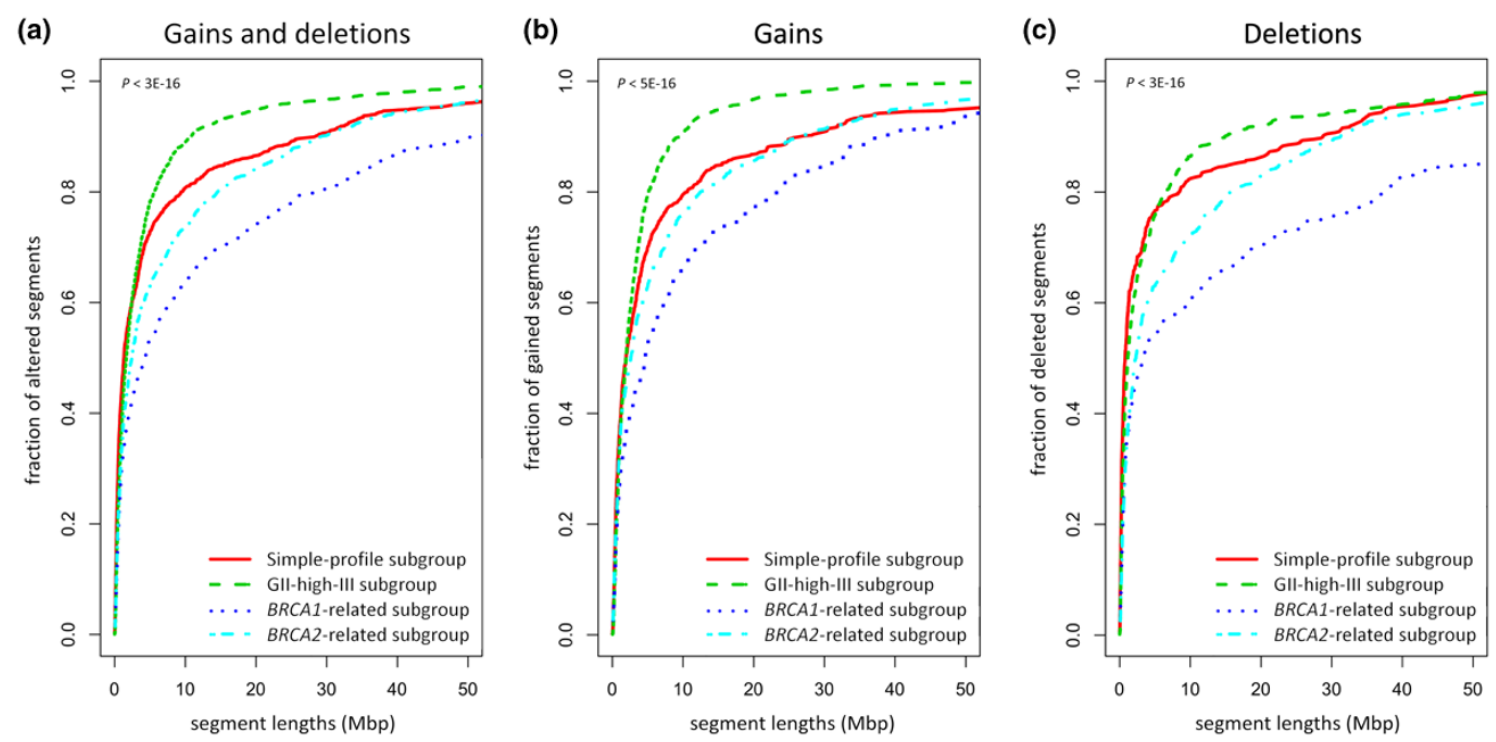

Quantitative analysis of the observed genome architecture patterns. Empirical cumulative distribution curves for segment lengths within each of the four identified subgroups were examined. The distribution of segment lengths for each of the identified subgroups are shown for all segments (a) altered in copy number, (b) gained in copy number and (c) deleted in copy number. The $P$-values in each of these comparisons were highly significant $\left(P<10^{-15}\right)$ determined through a Kruskal-Wallis hypothesis test.

ised by small copy number gains rather than deletions (Figures $4 \mathrm{~b}$ and $4 \mathrm{c}$ ). Pair-wise comparisons for the distributions in deleted segment lengths between subgroups demonstrates that each of the BRCA1- and BRCA2-related subgroups are significantly different from the simple- and/or Gll-high-III subgroups (Wilcoxon rank sum test, $P<10^{-11}$ ).

\section{Tumour phenotypes and their relation with genomic profiles}

The relation between the identified genomic subgroups and tumour phenotypes was examined using a selected panel of biomarkers analysed on TMAs. Tumour phenotypes were established as described in Cheang and colleagues by expression analysis of five biomarkers, ER, PR, HER-2, EGFR and CK5/6 on TMA sections [25]. Additionally, we examined the expression of CK8 and CK18 on these TMAs.

Clear trends for particular phenotypic properties were observed for the three genomic instability groups (Gll-high; Figures $5 \mathrm{a}$ and $5 \mathrm{~b}$ ) [see Additional data files 3 and 9]. The $B R C A 1$-related subgroup was enriched for tumours displaying non-luminal phenotypes (9 of 11, 82\%; Fisher's exact test, $P=0.0049)$ and grade $3+(8$ of $11,73 \%)$. Of the nine nonluminal tumours within this subgroup a total of eight were fully interpretable for all the five biomarkers and were thus further subdivided into basal-like ( 4 of $8,50 \%$ ), non-luminal HER-2 (2 of $8,25 \%$ ) and tumours negative for all five biomarkers, $5 \mathrm{NP}$, ( 2 of $8,25 \%$; Figure $5 \mathrm{a}$ ). The two luminal tumours within this subgroup displayed high ER expression (3+) and negativity for HER-2 amplification. The BRCA2-related subgroup was entirely composed of luminal tumours ( 9 of $9,100 \%)$. All but one of the tumours within this subgroup displayed high expression of ER $(\geq 2+; 8$ of $9,89 \%)$ and almost all were of grade 3+ ( 4 of $5,80 \%$ ). Four of the seven tumours displaying hyperintense ER staining $(>3+)$ were found within this subgroup (4 of 7,57\%; Fisher's exact test $P=0.0049$ ). All of the nine tumours within this subgroup were HER-2 negative (9 of 9, 100\%; Figure 5a). The Gll-high-III subgroup was almost entirely composed of luminal tumours (12 of $14,86 \%)$. This group of tumours displayed an unusually high frequency of high PR expression with IHC score 3+ (7 of 14, 50\%; Fisher's exact test $P=0.034)$ and with IHC score $\geq 2+(9$ of $14,64 \%$; Fisher's exact test $P=0.0072$; Figure $5 \mathrm{~b}$ ). Supporting this observation is the finding that two of the three tumours within the entire study group displaying hyper-intense staining of the PR gene $(>3+)$ were found within the Gll-high-IIl subgroup. It can be hypothesised here that the third component shown in Figure $5 \mathrm{~b}$ reflects differences in luminal vs. non-luminal phenotypes whereas the second component splits up two populations of luminal tumours that are different in terms of PR expression (Figure 5b) [see Additional data file 3].

The simple-profiles subgroup was found to represent a heterogeneous group of tumours in terms of their phenotypes. An important observation is that the luminal tumours within this subgroup displayed a trend towards lower tumour grade as compared with the luminal tumours within the more complex Gll-high subgroups (Chi-squared test for trend, $P=0.032$ ). However, non-luminal tumours within the simple-profile subgroup displayed a trend towards high tumour grade as compared with the luminal tumours within the same subgroup (Chisquared test for trend, $P=0.0015)$. 

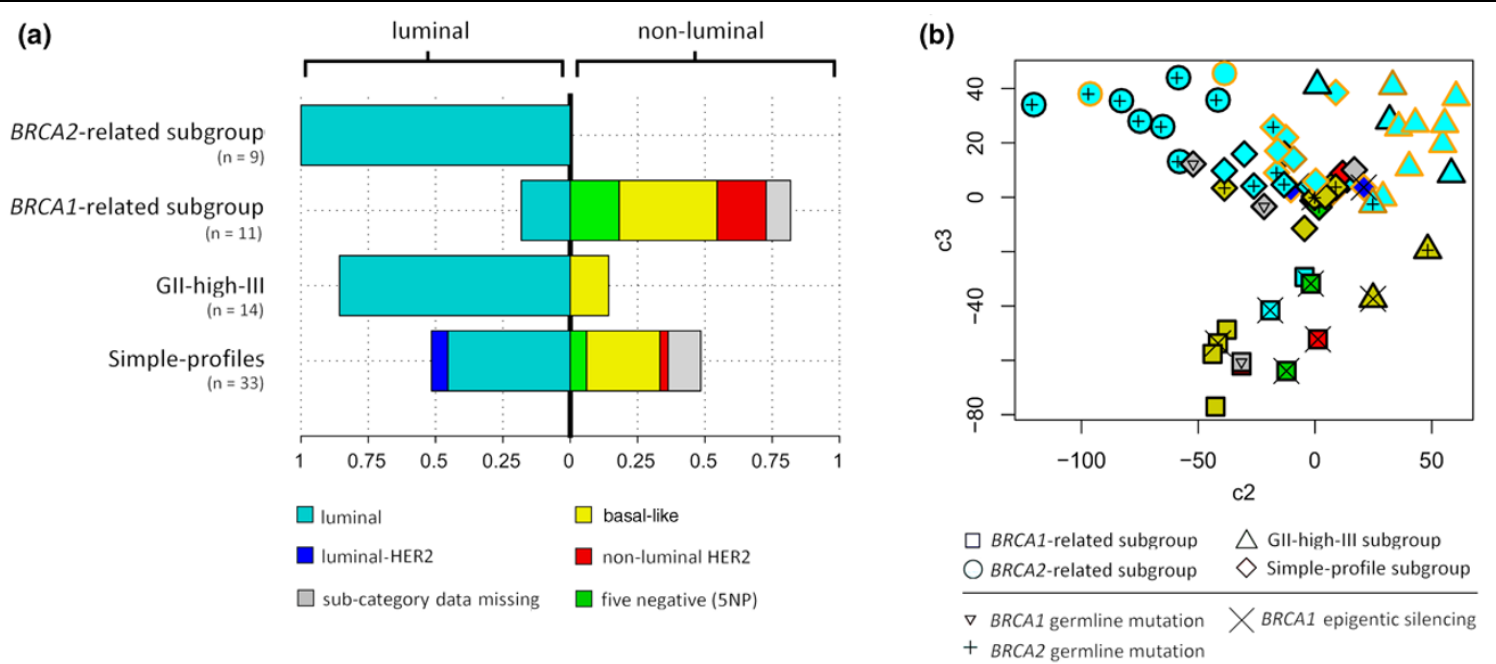

Tumour phenotypes in relation to the identified genomic subgroups. (a) Expression of oestrogen-receptor (ER), progesterone receptor (PR) and human epidermal growth factor receptor (HER)-2 was available in all cases enabling classification of all tumours as luminal or non-luminal. The tumours were then further subdivided using the five biomarker scheme based on expression analysis of ER, PR, HER-2, epidermal growth factor receptor (EGFR) and cytokeratin (CK) 5/6. The left part of each rectangle represents the proportion of luminal phenotypes within each of the four subgroups, as indicated, whereas the right part represents the proportion of non-luminal tumours. Sub-categories of these phenotypes are represented there within as proportions of either luminal or non-luminal phenotypes, see bottom of the figure. (b) Projection of all tumours through principal component analysis (PCA) is shown with cluster outcomes, BRCA status and the assigned tumour phenotypes indicated. Colours indicate tumour phenotypes matching those given at the bottom left panel with the addition of high PR expression immunohistochemistry scores $2+$ and $\geq 3+$ indicated by dark and light orange character outlines, respectively. Cluster memberships and BRCA status are indicated as shown at the bottom of the figure. In terms of tumour phenotypes, it can be hypothesised that component three reflects differences in luminal vs. non-luminal phenotypes whereas component two separates two populations of luminal tumours, which relate to differential PR expression.

\section{Tumours displaying low genomic instability indices}

The observed heterogeneity within the simple-profile subgroup was further examined by hierarchical cluster analysis on the genomic profiles found within this subgroup. This analysis revealed a cluster of tumours $(n=11)$ characterised by very low genomic instability indices (mean of $0.029 \pm 0.026$ ) as compared with the other simple-profile tumours (Wilcoxon rank sum test, $P<10^{-5}$ ) and the rest of the cohort (Wilcoxon rank sum test, $P<10^{-6}$ ). This cluster of tumours displaying mostly 'flat' genomes included high frequency of non-luminal phenotypes ( 9 of $11,82 \%$ ) of which most were basal-like (7 of $9,78 \%$ ) and grade $3+$ (Figure 6). Although they are characterised by silent or flat genomes, these tumours occasionally show small spikes of alterations, including focal high-level amplifications and very small deletions. We observed that this cluster of silent-tumours $(n=11)$, referred to hereafter using the 'silent' prefix, more frequently displayed high expression of EGFR $(\geq 2+)$ gene products as compared with the rest of the cohort (Fisher's exact test, $P=0.0069$ ). Two of these five tumours with high EGFR expression displayed high-level amplification of the EGFR gene, which was not found in any other tumour within the study group [see Additional data file 10]. Importantly, the non-luminal tumours with silent genomes displayed an aggressive phenotype in terms of disease outcome (Figure 6). By contrast, the luminal tumours within the simple-profile subgroup displayed low tumour grade and few of these patients experienced relapse within 5 years suggesting non-aggressive disease (Figure 6).

Tumours derived from BRCA1 germline mutation carriers were not found within the cluster of 11 tumours displaying silent genomes. However, two familial BRCA2 tumours were found within this cluster, neither of which displayed deletion or allelic imbalance at the BRCA2 locus and both had an extremely low Gll, that is less than 0.034 , and were of basallike phenotype.

\section{Discussion}

The results presented here portray detailed views of genomic alterations in breast cancers and their relation with $B R C A$ abnormalities and tumour phenotypes. The purpose of this study was to examine the potential involvement of the BRCA1 and $B R C A 2$ genes in sporadic breast tumour development.

\section{A subset of sporadic tumours develop either BRCA1- or BRCA2-like patterns of genomic alterations}

Classification of genomic profiles through cluster analysis revealed four distinct subgroups of which two displayed high prevalence of tumours having either BRCA1- or BRCA2 abnormalities. These two subgroups, referred to as the $B R C A 1$ - and BRCA2-related subgroups respectively, displayed distinct patterns of genomic alterations and high instability indices. Importantly, our results show that sporadic 
Figure 6
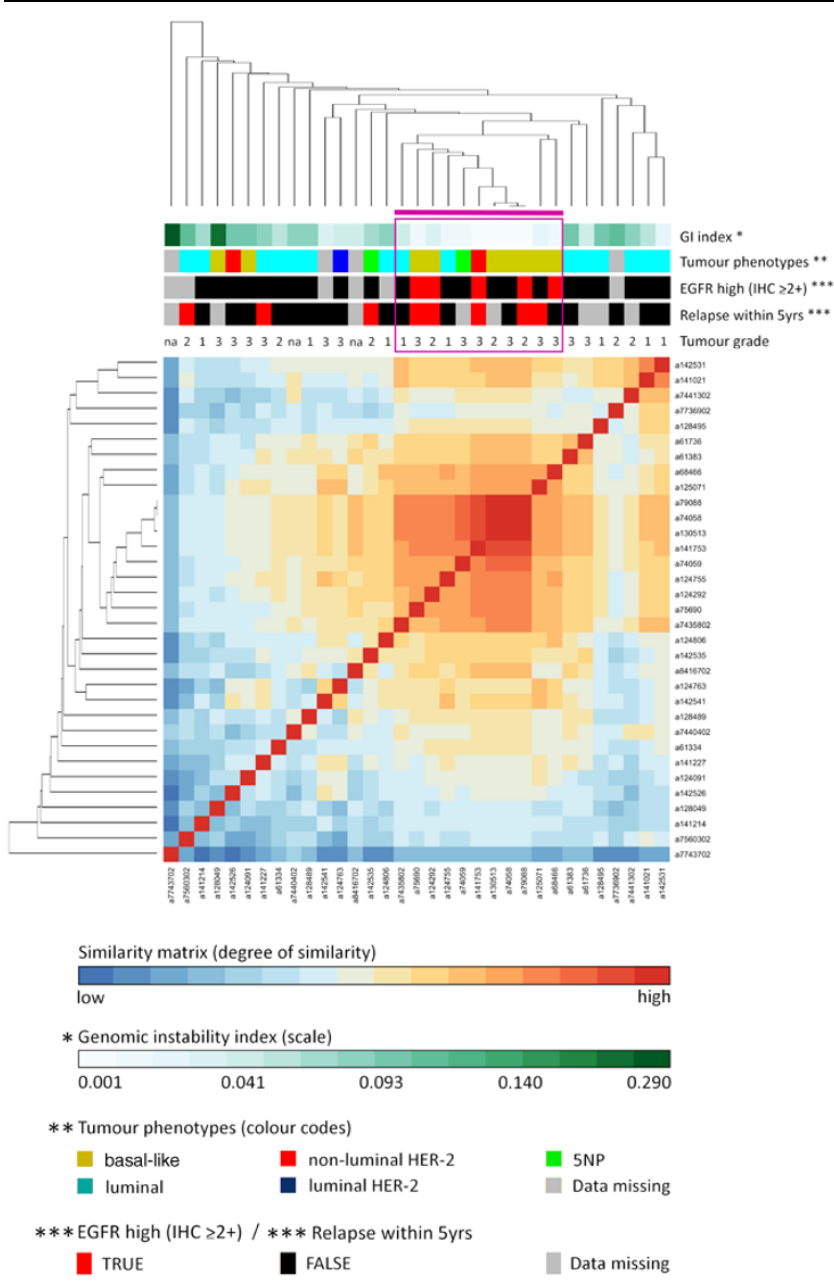

Hierarchical cluster analysis of genomic profiles within the simple-profiles subgroup. This analysis revealed a cluster of tumours $(n=11)$, purple bar and rectangle, characterised by very low genomic instability indices. This cluster was highly enriched with tumours of basal-like phenotypes with high expression of epidermal growth factor receptor (EGFR) being a prominent feature. These tumours generally displayed high tumour grade and an aggressive phenotype in terms of time to relapse.

tumours with epigenetic silencing of the $B R C A 1$ gene develop similar patterns of genomic alterations as tumours derived from $B R C A 1$ germline mutation carriers. This suggests that inactivation of the $B R C A 1$ gene through epigenetic silencing is an important event in sporadic breast tumour development. We found two tumours within this genomic subgroup displaying loss of BRCA1 expression without promoter methylation of the BRCA1 gene and both of these tumours expressed the basal marker CK5/6. Given the observations described above, it is reasonable to speculate that sporadic tumours displaying $B R C A 1$-like genomic alterations are promoted by defects linked with the BRCA1 gene function in genomic maintenance.
Interestingly, one sporadic tumour classified among the $B R C A 2$-related subgroup, which was otherwise exclusively comprised of tumours derived from $B R C A 2$ germline mutation carriers. This tumour displayed a deletion at the BRCA2 gene locus and gains in EMSY gene copy numbers. EMSY gene products are known to interact with and negatively regulate $B R C A 2$ proteins and this may link the BRCA2 gene with sporadic breast tumour development. Obviously, further research is needed to examine the relation between $E M S Y$ amplification and $B R C A 2$-like patterns of genomic alterations.

\section{BRCA-like genomic instability}

Although BRCA1- and BRCA2-related tumours develop through alterations affecting different regions in their genomes they showed similarities in their genomic architecture patterns with large segments of deletions being prominent. This suggests a similar mechanism by which these tumours acquire instability and we propose here that this might relate to the involvement of the BRCA1 and BRCA2 genes in error-free DNA repair of double-strand breaks through HR (homologous recombination). Inactivation of either $B R C A 1$ or $B R C A 2$ is generally thought to lead to the repair of double-strand breaks by error-prone mechanisms via non-homologous end joining [32,33]. DNA repair of double-strand breaks by non-homologous end joining can lead to errors leading to gains or losses of large segments of genomic material. This mechanism could underlie the characteristic type of genomic instability observed within the BRCA1- and BRCA2-related subgroups. Alternative but not mutually exclusive interpretations relate to the proposed roles of the BRCA genes in telomere maintenance and centrosome division $[4,34,35]$. By contrast, the third instability subgroup, GII-high-III, was found to display increased propensity to acquire small copy number gains which might relate to the previously proposed 'amplifier phenotypes' and possibly 'complex-firestorm patterns' in breast tumours $[27,31]$. The 7 kbp high-resolution array CGH analysis used in this study is crucial for distinguishing between tumour genomes characterised by small copy gains from those displaying large-scale instability patterns. This provided increased clarity in classification of breast tumours by their genomic profiles.

\section{Genomic alterations characterizing BRCA1- and BRCA2- related tumour development}

The genomic regions on chromosomes 4, 5 and 10 reported here to characterise the BRCA1-related subgroup overlap with those previously reported to distinguish tumours derived from $B R C A 1$ germline mutation carriers $[36,37]$. Because familial $B R C A 1$ tumours resemble basal-like tumours in terms of their phenotype it is of interest to note here that the genomic alterations that characterise the $B R C A 1$-related subgroup overlap with those associated with basal-like tumours [19].

The genomic alterations that were found to characterise $B R C A 2$-related tumour development overlap with those previously described in relation with familial BRCA2 tumours 
[36,38]. In addition, we found high-level amplifications at 1q43-q44 and deletions at chromosome 14q, which have not been described before in relation with familial BRCA2 tumour development. The detailed information on the locations of genomic alterations provided by the high-resolution $\mathrm{CGH}$ arrays used here allowed us to more clearly delineate the distinct genetic pathways undertaken by breast tumours displaying either BRCA1 or BRCA2 abnormalities.

Further research will be needed to examine the potential of the data presented here to predict $B R C A 1$ or BRCA2 abnormalities in an independent population of breast tumours or cell lines. The importance of establishing a simple and effective classification scheme to identify such tumours lies in the potential benefit of targeted therapy (PARP inhibitors, platinum drugs) for a much larger group of patients than the relatively few BRCA1 and BRCA2 germline mutation carriers.

\section{Tumour phenotypes in BRCA-related tumour development}

Tumours derived from $B R C A 1$ germline mutation carriers have previously been shown to predominantly display basal-like phenotypes [17,39]. In line with this we observed that tumours within the BRCA1-related subgroup primarily display nonluminal phenotypes of which basal-like phenotypes were the most prominent. However, we did identify a cluster of tumours characterised by low genomic instability indices and non-luminal phenotypes. These tumours were mostly of basal-like phenotypes and displayed an aggressive phenotype in terms of disease outcome. This observation demonstrates that a subset of non-luminal breast tumours do not develop towards large-scale genomic alterations supporting the hypothesis that these tumours represent biologically important disease entities [20]. Tumours derived from BRCA2 germline mutation carriers have previously been shown to primarily display luminal phenotypes and rarely overexpress HER-2 gene products and these findings were confirmed here [40]. Interestingly, we observed two familial-BRCA2 tumours without deletion or allelic imbalance at the $B R C A 2$ locus and these tumours did not display large-scale genomic instability. This raises the possibility that the natural history of some familial BRCA2 tumours does not involve loss of the wild-type BRCA2 allele or at least only partial loss as has been suggested before [41]. In this relation, it has been shown that cells heterozygous for a $B R C A 2$ mutation are associated with a phenotype $[42,43]$. Taken together, this suggests that a small subset of $B R C A 2$ tumours could be promoted by haploinsufficiency for the $B R C A 2$ gene.

The combined analysis of genomic alterations and tumour phenotypes, presented here, show that BRCA1- and BRCA2related tumours develop largely through different genetic pathways in terms of the regions altered, while also displaying distinct phenotypes. In light of the common roles for BRCA1 and $B R C A 2$ in genomic maintenance, this suggests that the observed phenotypic differences impose selective advantages for genomic alterations at distinct regions in the context of instability generated by BRCA-deficiency. This is in agreement with the results described by Melchor and colleagues showing the importance of ER status in familial and sporadic breast tumours [44]. However, we found two genomically distinct populations of luminal tumours that clearly differed in terms of PR expression. This finding is novel and demonstrates the importance of this factor in breast tumour development.

\section{Conclusions}

We have demonstrated using high-resolution genomic profiling coupled with analysis of tumour phenotypes that the development of a subset of sporadic breast tumours is similar to that of tumours derived from BRCA1- or BRCA2 germline mutation carriers. Tumours that develop BRCA1-like patterns of genomic alterations predominantly displayed high-grade, non-luminal phenotypes and high genomic instability. However, we also found a subset of high grade non-luminal tumours, mostly basal-like, that displayed very silent genomes characerised by low genomic instability indices supporting the notion of a novel subgroup of ER-negative breast tumours $[20,45]$.

Tumours within the BRCA1- and BRCA2-related genomic subgroups were found to acquire genomic alterations affecting distinct regions of their genomes while also displaying distinct tumour phenotypes. Given the common roles of the $B R C A$ gene products in genomic maintenance, this suggests that phenotypic differences between BRCA1- and BRCA2associated tumours impose selective advantages for distinct genomic alterations in the context of instability generated by $B R C A$-deficiency. Despite these differences, the BRCA1 and $B R C A 2$ genomic subgroups displayed clear similarities in their genome architecture patterns where large deletions were prominent suggesting a similar mechanism by which genomic instability is brought about, possibly relating to defects in DNA repair through HR. This genomic feature was observed in both familial and sporadic tumours displaying a BRCA1- or $B R C A 2-l i k e$ spectrum of genomic alterations. In this respect, it has been shown that cells with defective DNA repair by HR, including BRCA-deficient cells, are sensitive to agents that lead to DNA double-strand breaks such as PARP inhibitors and platinum agents [9]. The importance of the results presented here involve the potential benefits of targeted therapy through the use of agents that lead to double-strand breaks for a larger group of patients than the relatively few BRCA germline mutation carriers $[46,47]$.

\section{Competing interests}

The authors declare that they have no competing interests.

\section{Authors' contributions}

OAS contributed to the study design and performed the MSP and $\mathrm{CGH}$ analysis along with statistical analysis, data mining 
and writing of the manuscript. $\mathrm{KO}$ constructed the tissue microarrays and performed the IHC analysis. JGJ and OAS scored the IHC results. JGJ analysed tumour grade and OTJ contributed to clinical data analysis. MS performed the FISH analysis. SV contributed to the CGH analysis. JE conceived of the study, was in charge of its design and coordination and writing of the manuscript. All authors read and approved of the manuscript.

\section{Additional files}

The following Additional files are available online:

\section{Additional file 1}

An Excel file containing a table that lists antibodies used in the study for immunohistochemistry analysis on tissue microarray sections.

See http://www.biomedcentral.com/content/ supplementary/bcr2334-S1.xls

\section{Additional file 2}

A TIF file containing a figure that lists the proportion of the variance in the genomic data explained by each of the components derived from the principal component analysis (PCA).

See http://www.biomedcentral.com/content/ supplementary/bcr2334-S2.tiff

\section{Additional file 3}

A TIF file containing a figure that lists the projection of all tumours on components 1,2 and 3 through principal component analysis (PCA) is shown with cluster outcomes, BRCA status and tumour phenotypes indicated.

See http://www.biomedcentral.com/content/ supplementary/bcr2334-S3.tiff

\section{Additional file 4}

An Excel file containing a sample annotation table describing the cluster outcomes in terms of BRCA status, Al at the BRCA1 and BRCA2 loci, genomic instability index along with tumour phenotypes. See http://www.biomedcentral.com/content/ supplementary/bcr2334-S4.xls

\section{Additional file 5}

A TIF file containing a figure that shows genomic profiles derived from an independent set of five familial BRCA1 tumours were combined with the study group. All of these five familial BRCA1 tumours, indicated in grey colour, clustered among the tumours that constituted the previously defined BRCA1-related subgroup. The character codes represent cluster memberships with the five familial BRCA1 tumours included whereas the colour codes represent previously defined cluster memberships as shown on Figure $2 \mathrm{a}$ in the manuscript. Tumours derived from BRCA1 and BRCA2 germline mutation carriers are indicated, see bottom of the figure. See http://www.biomedcentral.com/content/ supplementary/bcr2334-S5.tiff

\section{Additional file 6}

An Excel file containing a table that lists genomic alterations characterising the distinct genetic pathways that were identified through cluster analysis of genomic profiles.

See http://www.biomedcentral.com/content/ supplementary/bcr2334-S6.xls

\section{Additional file 7}

A TIF file containing a figure that lists genomic alterations characterising each of the identified genetic pathways visualised using a frequency plot. The proportion of tumours showing gains (positive) and deletions (negative) are shown for each of the genomic regions examined. Additionally, the level of statistical significance is shown as determined through the modified Fisher's exact test comparing each genomic subgroup with the rest of the cohort.

See http://www.biomedcentral.com/content/ supplementary/bcr2334-S7.tiff

\section{Additional file 8}

A TIF file containing a figure that shows (upper panel) gains in copy numbers of the EMSY gene (11q13.5) observed in one sporadic tumour displaying BRCA2-like patterns of genomic alterations. (lower panel) fluorescence in situ hybridisation (FISH) analysis was performed for the EMSY gene region (RED) and centromere 11 (GREEN) verifying amplification of the EMSY gene in this tumour.

See http://www.biomedcentral.com/content/ supplementary/bcr2334-S8.tiff 


\section{Additional file 9}

A TIF file containing a figure that shows hierarchical cluster analysis of the biomarkers examined by immunohistochemistry on tissue microarray sections. Tumour phenotypes were established through analysis of these markers using the five biomarker scheme. The assigned tumour phenotypes are indicated on top of each heat map. See colour codes at the bottom of the figure.

See http://www.biomedcentral.com/content/ supplementary/bcr2334-S9.tiff

\section{Additional file 10}

A TIF file containing a figure that shows high expression of epidermal growth factor receptor (EGFR) gene products (only membrane staining was scored) in four of the nine non-luminal tumours displaying 'silent' genomes. High-level amplifications of the EGFR gene were found in two of these tumours and gain of the entire chromosome 7, where the EGFR gene resides, was found in one of them. High-level amplifications of the EGFR gene were not found anywhere else within the entire study group. (a) High expression of EGFR gene products $(\geq 2+)$ in four example tumours, all of which displaying 'silent' genomes. The immunohistochemistry scores are indicated in each case. (b) High-level amplifications of the EGFR gene were found in two tumours displaying 'silent' genomes viewed here in 37.5 $\mathrm{kb}$ resolution (5x). (c) Chromosome 7 viewed in $7 \mathrm{kbp}$ resolution $(1 \times)$ of the same example genome with highlevel amplification of the EGFR gene indicated. See http://www.biomedcentral.com/content/ supplementary/bcr2334-S10.tiff

\section{Acknowledgements}

We would like to thank Dr Sigridur Klara Bodvarsdottir for advice on the FISH analysis and review of the manuscript and Holmfridur Hilmarsdottir for $B R C A 1$ and BRCA2 germline mutation screening and technical assistance. We also thank the staff at Roche NimbleGen Systems for assistance with the array CGH analysis, Department of Pathology Landspitali University Hospital and Gudridur Olafsdottir for assistance with sample data and The Icelandic Cancer Society for facilities. This work was funded by Eimskipafelag University Fund (OAS), Gongum Saman (OAS), Icelandic Research Foundation Graduate Student Grants (OAS), The University of Iceland Research Fund, The Icelandic Centre for Research RANNIS and Margret Bjorgolfsdottir Memorial Fund (OAS, JEE).

\section{References}

1. Fackenthal JD, Olopade OI: Breast cancer risk associated with BRCA1 and BRCA2 in diverse populations. Nat Rev Cancer 2007, 7:937-948.

2. Collins N, McManus R, Wooster R, Mangion J, Seal S, Lakhani SR, Ormiston W, Daly PA, Ford D, Easton DF: Consistent loss of the wild type allele in breast cancers from a family linked to the
BRCA2 gene on chromosome 13q12-13. Oncogene 1995, 10:1673-1675.

3. Smith SA, Easton DF, Evans DG, Ponder BA: Allele losses in the region 17q12-21 in familial breast and ovarian cancer involve the wild-type chromosome. Nat Genet 1992, 2:128-131.

4. Gudmundsdottir K, Ashworth A: The roles of BRCA1 and BRCA2 and associated proteins in the maintenance of genomic stability. Oncogene 2006, 25:5864-5874.

5. Matsuoka S, Ballif BA, Smogorzewska A, McDonald ER 3rd, Hurov $\mathrm{KE}$, Luo J, Bakalarski CE, Zhao Z, Solimini N, Lerenthal Y, Shiloh Y, Gygi SP, Elledge SJ: ATM and ATR substrate analysis reveals extensive protein networks responsive to DNA damage. Science 2007, 316:1160-1166.

6. Greenberg RA, Sobhian B, Pathania S, Cantor SB, Nakatani Y, Livingston DM: Multifactorial contributions to an acute DNA damage response by BRCA1/BARD1-containing complexes. Genes Dev 2006, 20:34-46.

7. Yang H, Li Q, Fan J, Holloman WK, Pavletich NP: The BRCA2 homologue Brh2 nucleates RAD51 filament formation at a dsDNA-ssDNA junction. Nature 2005, 433:653-657.

8. Wang W: Emergence of a DNA-damage response network consisting of Fanconi anaemia and BRCA proteins. Nat Rev Genet 2007, 8:735-748.

9. Martin SA, Lord CJ, Ashworth A: DNA repair deficiency as a therapeutic target in cancer. Curr Opin Genet Dev 2008, 18:80-86.

10. Futreal PA, Liu Q, Shattuck-Eidens D, Cochran C, Harshman K, Tavtigian S, Bennett LM, Haugen-Strano A, Swensen J, Miki Y: BRCA1 mutations in primary breast and ovarian carcinomas. Science 1994, 266:120-122.

11. Lancaster JM, Wooster R, Mangion J, Phelan CM, Cochran C, Gumbs C, Seal S, Barfoot R, Collins N, Bignell G, Patel S, Hamoudi R, Larsson C, Wiseman RW, Berchuck A, lglehart JD, Marks JR, Ashworth A, Stratton MR, Futreal PA: BRCA2 mutations in primary breast and ovarian cancers. Nat Genet 1996, 13:238-240.

12. Wei M, Grushko TA, Dignam J, Hagos F, Nanda R, Sveen L, Xu J, Fackenthal J, Tretiakova M, Das S, Olopade OI: BRCA1 promoter methylation in sporadic breast cancer is associated with reduced BRCA1 copy number and chromosome 17 aneusomy. Cancer Res 2005, 65:10692-10699.

13. Birgisdottir V, Stefansson OA, Bodvarsdottir SK, Hilmarsdottir $H$, Jonasson JG, Eyfjord JE: Epigenetic silencing and deletion of the BRCA1 gene in sporadic breast cancer. Breast Cancer Res 2006, 8:R38.

14. Hughes-Davies L, Huntsman D, Ruas M, Fuks F, Bye J, Chin SF, Milner J, Brown LA, Hsu F, Gilks B, Nielsen T, Schulzer M, Chia S, Ragaz J, Cahn A, Linger L, Ozdag H, Cattaneo E, Jordanova ES, Schuuring E, Yu DS, Venkitaraman A, Ponder B, Doherty A, Aparicio S, Bentley D, Theillet C, Ponting CP, Caldas C, Kouzarides T: EMSY links the BRCA2 pathway to sporadic breast and ovarian cancer. Cell 2003, 115:523-535.

15. Perou CM, Sorlie T, Eisen MB, Rijn M van de, Jeffrey SS, Rees CA, Pollack JR, Ross DT, Johnsen H, Akslen LA, Fluge O, Pergamenschikov A, Williams C, Zhu SX, Lonning PE, Borresen-Dale AL, Brown PO, Botstein D: Molecular portraits of human breast tumours. Nature 2000, 406:747-752.

16. Chin K, DeVries S, Fridlyand J, Spellman PT, Roydasgupta R, Kuo WL, Lapuk A, Neve RM, Qian Z, Ryder T, Chen F, Feiler H, Tokuyasu T, Kingsley C, Dairkee S, Meng Z, Chew K, Pinkel D, Jain A, Ljung BM, Esserman L, Albertson DG, Waldman FM, Gray JW: Genomic and transcriptional aberrations linked to breast cancer pathophysiologies. Cancer Cell 2006, 10:529-541.

17. van't Veer LJ, Dai H, Vijver MJ van de, He YD, Hart AA, Mao M, Peterse HL, Kooy K van der, Marton MJ, Witteveen AT, Schreiber GJ, Kerkhoven RM, Roberts C, Linsley PS, Bernards R, Friend SH: Gene expression profiling predicts clinical outcome of breast cancer. Nature 2002, 415:530-536.

18. Turner NC, Reis-Filho JS, Russell AM, Springall RJ, Ryder K, Steele D, Savage K, Gillett CE, Schmitt FC, Ashworth A, Tutt AN: BRCA1 dysfunction in sporadic basal-like breast cancer. Oncogene 2007, 26:2126-2132.

19. Bergamaschi A, Kim YH, Wang P, Sorlie T, Hernandez-Boussard T, Lonning PE, Tibshirani R, Borresen-Dale AL, Pollack JR: Distinct patterns of DNA copy number alteration are associated with different clinicopathological features and gene-expression subtypes of breast cancer. Genes Chromosomes Cancer 2006, 45:1033-1040. 
20. Chin SF, Teschendorff AE, Marioni JC, Wang $Y$, Barbosa-Morais NL, Thorne NP, Costa JL, Pinder SE, Wiel MA van de, Green AR, Ellis IO, Porter PL, Tavare S, Brenton JD, Ylstra B, Caldas C: Highresolution aCGH and expression profiling identifies a novel genomic subtype of ER negative breast cancer. Genome Biol 2007, 8:R215.

21. Thorlacius S, Olafsdottir G, Tryggvadottir L, Neuhausen S, Jonasson JG, Tavtigian SV, Tulinius H, Ogmundsdottir HM, Eyfjord JE: A single BRCA2 mutation in male and female breast cancer families from Iceland with varied cancer phenotypes. Nat Genet 1996, 13:117-119.

22. Bergthorsson JT, Jonasdottir A, Johannesdottir G, Arason A, Egilsson V, Gayther S, Borg A, Hakanson S, Ingvarsson S, Barkardottir RB: Identification of a novel splice-site mutation of the BRCA1 gene in two breast cancer families: screening reveals low frequency in Icelandic breast cancer patients. Hum Mutat 1998:S195-197.

23. Selzer RR, Richmond TA, Pofahl NJ, Green RD, Eis PS, Nair P, Brothman AR, Stallings RL: Analysis of chromosome breakpoints in neuroblastoma at sub-kilobase resolution using finetiling oligonucleotide array CGH. Genes Chromosomes Cancer 2005, 44:305-319.

24. Gentleman R, Carey VJ, Huber W, Irizarry R, Dudoit S: Bioconductor: open software development for computational biology and bioinformatics. Genome Biol 2004, 5:R80.

25. Cheang MC, Voduc D, Bajdik C, Leung S, McKinney S, Chia SK, Perou CM, Nielsen TO: Basal-like breast cancer defined by five biomarkers has superior prognostic value than triple-negative phenotype. Clin Cancer Res 2008, 14:1368-1376.

26. Olshen $A B$, Venkatraman $E S$, Lucito $R$, Wigler M: Circular binary segmentation for the analysis of array-based DNA copy number data. Biostatistics 2004, 5:557-572.

27. Fridlyand J, Snijders AM, Ylstra B, Li H, Olshen A, Segraves R, Dairkee S, Tokuyasu T, Ljung BM, Jain AN, McLennan J, Ziegler J, Chin K, Devries S, Feiler H, Gray JW, Waldman F, Pinkel D, Albertson DG: Breast tumor copy number aberration phenotypes and genomic instability. BMC Cancer 2006, 6:96.

28. Pollack JR, Sorlie T, Perou CM, Rees CA, Jeffrey SS, Lonning PE, Tibshirani R, Botstein D, Borresen-Dale AL, Brown PO: Microarray analysis reveals a major direct role of DNA copy number alteration in the transcriptional program of human breast tumors. Proc Natl Acad Sci USA 2002, 99:12963-12968.

29. Hosack DA, Dennis G Jr, Sherman BT, Lane HC, Lempicki RA: Identifying biological themes within lists of genes with EASE. Genome Biol 2003, 4:R70.

30. Fridlyand J, Snijders AM, Ylstra B, Li H, Olshen A, Segraves R, Dairkee S, Tokuyasu T, Ljung BM, Jain AN, McLennan J, Ziegler J, Chin K, Devries S, Feiler H, Gray JW, Waldman F, Pinkel D, Albertson DG: Breast tumor copy number aberration phenotypes and genomic instability. BMC Cancer 2006, 6:96.

31. Hicks J, Krasnitz A, Lakshmi B, Navin NE, Riggs M, Leibu E, Esposito D, Alexander J, Troge J, Grubor V, Yoon S, Wigler M, Ye K, Borresen-Dale AL, Naume B, Schlicting E, Norton L, Hagerstrom T, Skoog L, Auer G, Maner S, Lundin P, Zetterberg A: Novel patterns of genome rearrangement and their association with survival in breast cancer. Genome Res 2006, 16:1465-1479.

32. Snouwaert JN, Gowen LC, Latour AM, Mohn AR, Xiao A, DiBiase L, Koller BH: BRCA1 deficient embryonic stem cells display a decreased homologous recombination frequency and an increased frequency of non-homologous recombination that is corrected by expression of a brca1 transgene. Oncogene 1999, 18:7900-7907.

33. Tutt A, Bertwistle D, Valentine J, Gabriel A, Swift S, Ross G, Griffin $C$, Thacker J, Ashworth A: Mutation in Brca2 stimulates errorprone homology-directed repair of DNA double-strand breaks occurring between repeated sequences. EMBO J 2001, 20:4704-4716.

34. Eyfjord JE, Bodvarsdottir SK: Genomic instability and cancer: networks involved in response to DNA damage. Mutat Res 2005, 592:18-28.

35. Ayouaz A, Raynaud C, Heride C, Revaud D, Sabatier L: Telomeres: hallmarks of radiosensitivity. Biochimie 2008, 90:60-72.

36. Jonsson G, Naylor TL, Vallon-Christersson J, Staaf J, Huang J, Ward MR, Greshock JD, Luts L, Olsson H, Rahman N, Stratton M, Ringner M, Borg A, Weber BL: Distinct genomic profiles in hereditary breast tumors identified by array-based comparative genomic hybridization. Cancer Res 2005, 65:7612-7621.
37. van Beers EH, van Welsem T, Wessels LF, Li Y, Oldenburg RA, Devilee P, Cornelisse CJ, Verhoef S, Hogervorst FB, van't Veer LJ, Nederlof PM: Comparative genomic hybridization profiles in human BRCA1 and BRCA2 breast tumors highlight differential sets of genomic aberrations. Cancer Res 2005, 65:822-827.

38. Tirkkonen $\mathrm{M}$, Johannsson $\mathrm{O}$, Agnarsson $\mathrm{BA}$, Olsson $\mathrm{H}$, Ingvarsson S, Karhu R, Tanner M, Isola J, Barkardottir RB, Borg A, Kallioniemi OP: Distinct somatic genetic changes associated with tumor progression in carriers of BRCA1 and BRCA2 germ-line mutations. Cancer Res 1997, 57:1222-1227.

39. Foulkes WD, Stefansson IM, Chappuis PO, Begin LR, Goffin JR, Wong N, Trudel M, Akslen LA: Germline BRCA1 mutations and a basal epithelial phenotype in breast cancer. J Natl Cancer Inst 2003, 95:1482-1485.

40. Bane AL, Beck JC, Bleiweiss I, Buys SS, Catalano E, Daly MB Giles G, Godwin AK, Hibshoosh H, Hopper JL, John EM, Layfield L, Longacre T, Miron A, Senie R, Southey MC, West DW, Whittemore AS, $\mathrm{Wu} \mathrm{H}$, Andrulis IL, O'Malley FP: BRCA2 mutation-associated breast cancers exhibit a distinguishing phenotype based on morphology and molecular profiles from tissue microarrays. Am J Surg Patho/ 2007, 31:121-128.

41. King TA, Li W, Brogi E, Yee CJ, Gemignani ML, Olvera N, Levine DA, Norton L, Robson ME, Offit K, Borgen PI, Boyd J: Heterogenic loss of the wild-type BRCA allele in human breast tumorigenesis. Ann Surg Oncol 2007, 14:2510-2518.

42. Warren M, Lord CJ, Masabanda J, Griffin D, Ashworth A: Phenotypic effects of heterozygosity for a BRCA2 mutation. Hum Mol Genet 2003, 12:2645-2656.

43. Kote-Jarai Z, Matthews L, Osorio A, Shanley S, Giddings I, Moreews F, Locke I, Evans DG, Eccles D, Carrier Clinic Collaborators, Williams RD, Girolami M, Campbell C, Eeles R: Accurate prediction of BRCA1 and BRCA2 heterozygous genotype using expression profiling after induced DNA damage. Clin Cancer Res 2006, 12:3896-3901.

44. Melchor L, Honrado E, Huang J, Alvarez S, Naylor TL, Garcia MJ, Osorio A, Blesa D, Stratton MR, Weber BL, Cigudosa JC, Rahman $\mathrm{N}$, Nathanson KL, Benitez J: Estrogen receptor status could modulate the genomic pattern in familial and sporadic breast cancer. Clin Cancer Res 2007, 13:7305-7313.

45. Herschkowitz JI, Simin K, Weigman VJ, Mikaelian I, Usary J, Hu Z, Rasmussen KE, Jones LP, Assefnia S, Chandrasekharan S, Backlund MG, Yin Y, Khramtsov Al, Bastein R, Quackenbush J, Glazer RI, Brown PH, Green JE, Kopelovich L, Furth PA, Palazzo JP, Olopade OI, Bernard PS, Churchill GA, Van Dyke T, Perou CM: Identification of conserved gene expression features between murine mammary carcinoma models and human breast tumors. Genome Biol 2007, 8:R76.

46. Fong PC, Boss DS, Yap TA, Tutt A, Wu P, Mergui-Roelvink M, Mortimer P, Swaisland H, Lau A, O'Connor MJ, Ashworth A, Carmichael J, Kaye SB, Schellens JH, de Bono JS: Inhibition of poly(ADP-ribose) polymerase in tumors from BRCA mutation carriers. N Engl J Med 2009, 361:123-134.

47. Moule R, Sohaib A, Eeles R: Dramatic Response to Platinum in a Patient with Cancer with a Germline BRCA2 Mutation. Clin Oncol (R Coll Radiol) 2009, 21:444-447. 